\title{
Simulation of Synchronous Motor Power driven System for EPS Based on SVPWM-DTC
}

\author{
XueFeng Ye $\mathrm{e}^{1, \mathrm{a}}$, ZuHua Fang ${ }^{1, \mathrm{~b}}$, Ying Sun ${ }^{1, \mathrm{c}}, \mathrm{GJ} \mathrm{Guo}^{1, \mathrm{~d}}$ and Jiale Wang ${ }^{1, \mathrm{e}}$ \\ ${ }^{1}$ College of information, mechanical and electrical engineering, Shanghai Normal University, No.100, \\ Haisi road, Shanghai 201418,China \\ austcplato@163.com, ${ }^{\mathrm{b}}$ (corresponding author) \\ zuhfang@shnu.edu.cn, 'sy168@shnu.edu.cn, d937938544@qq.com, ewjl_0017@163.com
}

Keywords: Sinusoidal space vector modulation algorithm, Direct torque control, Vector control, Torque ripple, Stator flux

\begin{abstract}
DTC (Direct Torque Control) with the torque and stator flux linkage as control variables directly, has the advantage of quick dynamic torque response, good anti-interference performance is also as an advantage, especially suitable for vehicle EPS power driven system to the requirement for the fast torque response, and the SVPWM (Space Vector Modulation Sine Wave) compared with the traditional PWM modulation ,the SVPWM inverter modulation method has the advantages of high utilization rate in DC bus voltage and small harmonic components. So it has been widely used in speed control system. Based on MATLAB / Simulink simulation platform, using the DTC with a new simulation model of EPS permanent magnet synchronous motor vector control system driven with lower harmonic characteristics of SVPWM modulation method combining elaborated DTC PMSM mathematical model based on SVPWM control principle .A large number of experimental results shows that this method which based on the control of SVPWM vector control compared with the conventional torque control method has a good dynamic performance, small torque ripple, etc.It can be a proved effective and rational model for EPS driven motor control system, and also provides a theoretical basis and related reference for overall design .
\end{abstract}

\section{Introduction}

Automotive electronic power steering system (EPS) is the core of the car to complete the movement direction control power auxiliary devices, it has been widely used in high-grade cars and electric cars, In order to obtain good dynamical characteristics and handle performance, and along with the rapid development of the new Power electronic devices and micro controller, power steering system has shifted from the initial hydraulic power system (HPS) gradually to the electronic power steering system (Electronic Power Steering, EPS) transition evolve. Rare earth permanent magnet materials rotor in PMSM, and the simple structure and easy maintenance, small rotational inertia, high power density, the potential for the sine wave brought low torque ripple, it has become a high EPS preferred performance booster drive system PMSM. To further reduce torque ripple and harmonic components, improving dynamic response performance, we will introduce SVPWM modulation techniques and ideas of DTC (Direct Torque Control, DTC) to PMSM speed control system, first established VSI ( voltage source inverter) of SVPWM model,then establish a complete DTC-SVPWM simulation model of PMSM, by comparing the calculated reference PMSM actual torque and the stator flux of the sub-torque with the flux tracking expectations ${ }^{[1]}$,to establish a Optimal model vector SVPWM switch off table, enabling the PMSM motor torque, speed and other parameters of rapid adjustment and dynamic response.

\section{Mathematical model of power motor using PMSM}

Permanent magnet synchronous motor is an important category of the motor, the rotor magnetic field produced by rare earth permanent magnet materials, the permanent magnets on the rotor produce a magnetic field, thus eliminating the coil excitation, and compared with specifications of the induction 
motor, the theory of energy conservation and efficiency can be improved by more than 10\%. PMSM motor has the nature of sine wave counter electromotive force, so the input of the motor stator current must be a sine wave to produce a constant torque output.

Based on establishing a three-phase bridge type Y connection ABC all-digital state equation of the motor stator static coordinate system, the stator voltage equation matrix form is as follows ${ }^{[1]}$ :

$$
\left[\begin{array}{l}
u a \\
u b \\
u c
\end{array}\right]=\left[\begin{array}{llll}
R s & & \\
& R s & \\
& & R s
\end{array}\right]\left[\begin{array}{l}
i a \\
i b \\
i c
\end{array}\right]+\left[\begin{array}{lll}
L-M & & \\
& L-M & \\
& & L-M
\end{array}\right] \frac{d}{d t}\left[\begin{array}{c}
i a \\
i b \\
i c
\end{array}\right]+\left[\begin{array}{c}
E a \\
E b \\
E c
\end{array}\right]
$$

ua, ub, uc is the stator three phase voltage, and the Rs is the three-phase stator winding resistance, for stator winding inductance is $\mathrm{L}, \mathrm{M}$ is the mutual inductance between the stator ,and Ea, Eb, Ec is three-phase stator produce counter electromotive force (Back-EMF), Fig.1 is the circuit equivalent figure for PMSM motor.

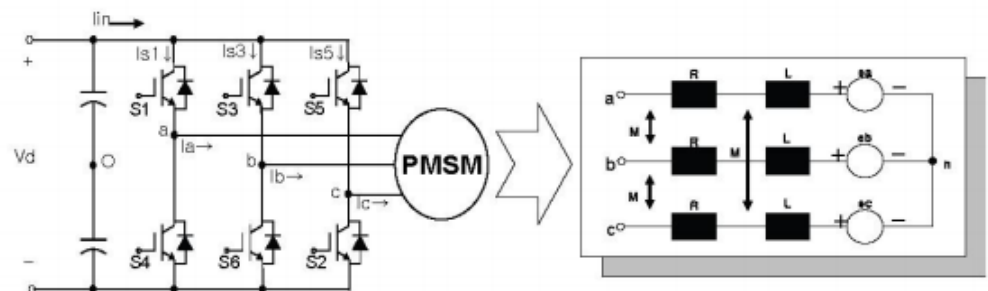

Fig.1 Three-phase VSI inverter PMSM system and its dynamic mathematical model of the equivalent circuit diagram

\section{Control principle based on SVPWM--DTC}

SVPWM-DTC control method see the motor and the inverter as a whole, on the basis of traditional DTC control strategies on a sector divided between each time slice corresponding to the PWM cycle of a cell, different linear combinations of synthesized over The voltage space vector(see Fig.2), thus approaching the ideal circular rotating magnetic field to form a smooth output torque,a total of three binary form eight different combinations of switches, six of the non-zero voltage space vector of the stator three-phase coordinate Voltage divided into six sectors, (000) and (111) are two special sectors located in the center of the voltage vector,they are for a linear combination of the nonzero-voltage vector space time insertion supplement ${ }^{[2][5]}$. Pairwise sequence of the power transistor conduction is generally: $120^{\circ}$ electrical angle, the upper and lower leg of the three-phase power of the same bridge arm of the tube,They can not be turned on the same time, otherwise it will form a power short-circuit, it is generally by inserting the dead time to avoid, insert the dead time is generally about 5-20 us .

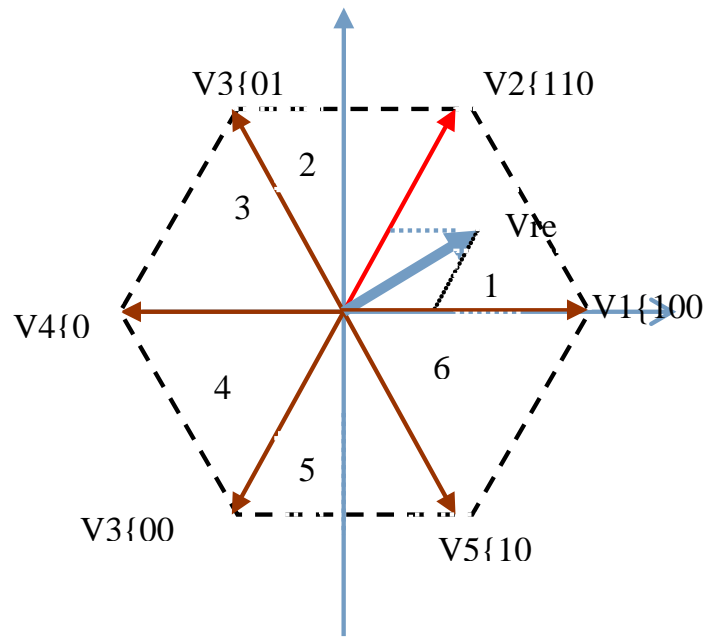

Fig .2 . Eight basic voltage space vector and voltage vector 


\section{Simulation Analysis}

DTC technique has been proposed for calculations and controls stator flux linkage and torque of PMSM directly to achieve high dynamic performance in the stator coordinate system. A block diagram of DTC with PMSM is shown in below Fig.3. $i_{s d}$ and $i_{s q}$ are the components of $i$ in the d-q axis, They can be obtained from the phase current sampling values through Clark Coordinate Transformation and Park Coordinate transformation. Then $\psi_{s q}, \psi_{s d}$ and $T e$ could be estimated by $i_{s d}$ and $i_{s q}$, this system uses three-way closed-loop control of speed, flux linkage and torque. Adopt speed deviation $\Delta \omega r$ as input value, outer loop Proportional Integral (PI) controller outputs $T_{e}{ }^{*}$ [3] , which is the given value of the torque loop. Then take torque deviation $\Delta T e$ as input value,torque loop PI controller outputs $d \delta$ is the correction value of $\delta$, which is the angle between $\psi_{P M}$ and $\psi_{s}$,

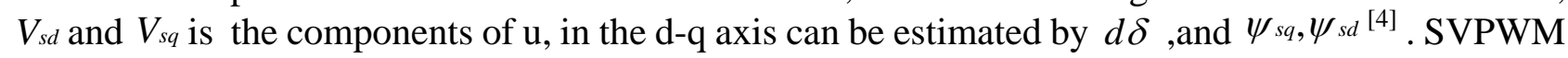
control signals can be generated through inverse Park Transformation , and then drive PMSM motor in EPS. And flux linkage estimator can be expressed as:

$$
\left\{\begin{array}{l}
\psi_{s d}=L_{s d} i_{s d}+\psi_{P M} \\
\psi_{s q}=L_{s q} i_{s q} \\
\left|\psi_{s r}\right|=\sqrt{\psi_{s d}^{2}+\psi_{s q}^{2}}
\end{array}\right.
$$

Voltage estimator can be expressed as:

$$
\left\{\begin{array}{l}
v_{s q}=R s i_{s q}+\frac{d \psi_{s q}}{d t}+\omega \psi_{s d} \\
v_{s d}=R s i_{s d}+\frac{d \psi s d}{d t}-\omega \psi_{s q}
\end{array}\right.
$$

where dt isthe flux linkage sampling time, $\psi_{s r} *$ is the given value of torque stator flux linkage.

\section{A. Matlab simulation principle and block diagram}

In order to verify the effective control strategy type and feasibility, based on MATLAB simulation platform to build a simulink simulation system as Fig.3:

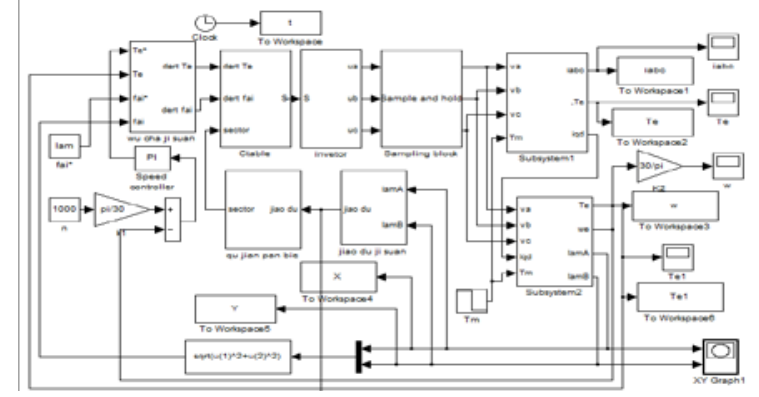

Fig.3.overall block diagram of MATLAB/simulink simulation based on DTC-SVPWM

\section{B. Simulation results and analysis}

Simulation Settings are as follows: the simulation time is $0.2 \mathrm{~S}$, DC bus voltage $311 \mathrm{v}$, three-phase stator resistance is $2.875 \Omega$, the permanent magnet rotor flux is $0.3 \mathrm{~Wb}$, and direct axis inductance $\mathrm{Ld}$ $=\mathrm{Lq}$ is $8.5 \mathrm{mH}$, motor pole pairs numbers P equals 4, PWM modulation frequency is $20 \mathrm{kHz}$. Fig.4 shows for Speed response graph at 1500rpm reference speed when the sudden increase or dump in the load torque in 0.1 seconds ,Fig. 5 shows for reference speed at $1500 \mathrm{rpm}$ and load torque in 0.1 seconds from $3 \mathrm{Nm}$ suddenly reduced to $1 \mathrm{~N} . \mathrm{m}$ and suddenly increased from $2 \mathrm{Nm}$ to $4 \mathrm{Nm}$ in the load torque the torque response figure,As shown in beleow, When the load torque decline suddenly,the output torque is temporarily greater than the load torque, motor is speeding until after a short time acceleration before output torque and load torque to achieve equilibrium state, and then the motor will maintain the stable reference velocity .Seen from Figures 4 and 5, the torque and speed response of the system is quickly which can meet the EPS system for torque and speed requirements of fast response request. 

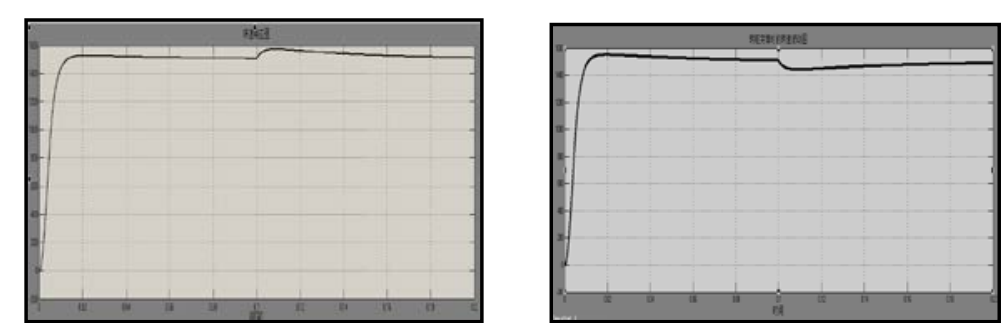

Fig.4. Speed response graph at 1500rpm when the sudden increase or dump in the load torque
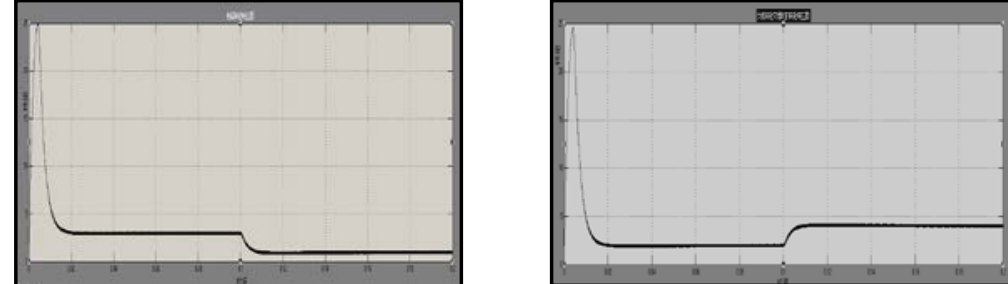

Fig.5. Torque response when the sudden increase or dump in the load torque
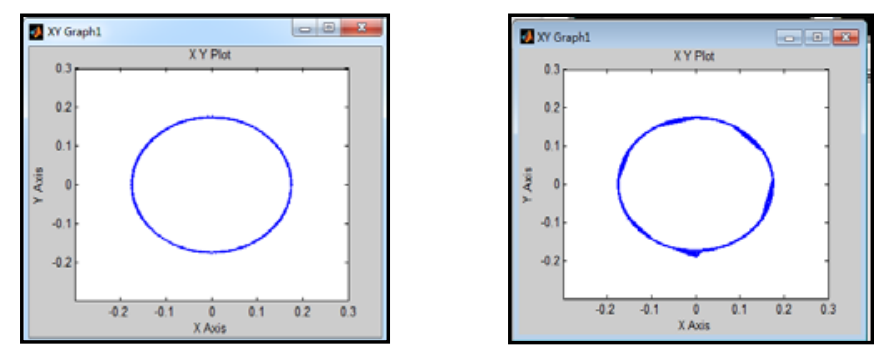

Fig.6. Comparison Chart of flux tracing circular map based on SVPWM-DTC control system and the traditional DTC control system.

Seen from Fig.6, It is Visible that the EPS PMSM driven motor system based on SVPWM - DTC control system compared with the traditional DTC control flux fluctuation significantly reduced.

\section{Conclusion}

It Can be seen from the above flux tracing waveform, EPS driven motor using PMSM based on DTC and SVPWM control system of magnetic chain round smooth, round neat, flux ripple decrease obviously, the dynamic torque response quickly and small torque ripple, torque ripple when load mutation is small, which verified the validity and feasibility of this control strategy.

\section{Acknowledgment}

This work was financially supported by the Research Program of Science and technology Committee of Shanghai (12160503000).

\section{References}

[1] L.Zhong, M.F.Rahman, W. YHu, etal. Analysis of direct torque control in permanent magnet synchronous motor drives[J].IEEE Transaction Power Electron, 2013, Vo1.12, No.3, pp.528-536

[2] L.Zhong, M.F.Rahman, W.Y Hu, etal. A direct torque controlled interior Permanent magnet synchronous motor drive incorporating field weakening.IEEE Transactions On Industry Applications, 2012, Vo1.34, No.6

[3]Li Y, Liu J, Ma J, Yu Q.A Simplified Voltage Vector Selection Strategy for Direct TorqueControl[J].TELKOMNIKA IndonesianJournal of Electrical Engineerin -g,2011,9(3):539-546. [4] M.J.Corley, R.D.Lorenz. Rotor position and velocity estimation for a salient-pole permanent magnet synchronous machine at standstill and high speeds[J].IEEE Transactions On Industry Applications, 2011, Vo1.34, No.4, pp.784-789

[5] Xiaoting Ye, Tao Zhang, "Direct Torque Control of Permanent Magnet Synchronous Motor Using SpaceVector Modulation", Proc. IEEE Chinese Control and Decision Conference pp.1450-1453, 2010 